\title{
Other Papers
}

\section{Petra Anic* \\ Domagoj Roguljic * \\ Domagoj Švegar*}

\section{What do students do in their free time and why?}

\begin{abstract}
Numerous studies have explored what people do in their free time, but only a few of them have tried to explain why. In Study 1 we therefore aimed to obtain a detailed picture of the ways in which students spend their free time, but also we wanted to investigate their motivation for engaging in a specific activity that they consider to be their favourite. We found that the highest percentage of 585 students, who participated in Study 1, spend most of their free time on social interactions, reading and leisure with family. However, although they did not spend much time on physical activities, participants reported them as their favourite ones. An analysis of variance showed no differences in hedonic motives for free time activities, while eudaimonic motives did differ. In Study 2, we investigated intrinsic motivation for physical exercise on a new sample of 202 students, and found that recreational athletes have significantly higher intrinsic motivation compared to physically less active participants.
\end{abstract}

Keywords: physical activity, intrinsic motivation, leisure, hedonic motives, eudiamonic motives

\section{Introduction}

Every week people spend many hours working, going to school or being engaged in some form of other, often imposed, duty or activity. Yet, there is still a huge amount of time, according to some authors even $40-50 \%$ of the time spent awake (Larson \& Verma, 1999), that is qualified as free time or leisure.

Free time or leisure (used as synonyms in this paper) may be defined in different ways. According to some authors, all the activities a person does when not working can be considered to be leisure (Brightbill, 1960; Smigel, 1963). Other authors (Massimini \& Carli, 1998) question this, and ask whether activities that are entertaining and relaxing, such as watching $\mathrm{TV}$, but are also characterized by boredom and apathy and a lack of intrinsic motivation, can also be qualified as leisure? If the characteristics of free time activities listed in the work of Larson and Verma (1999) are taken into account, for example that they are voluntary, intrinsically motivated, that they demand a higher degree of self-initiative, regulation and organization than work (or school), then perhaps TV watching cannot be considered to be a leisure activity. Many papers have been written in an attempt to solve this dilemma, and they provide different solutions. One of the best known is the two-dimensional typology given by Kleiber, Walker and Mannell (2011): the type of phenomena (objective and subjective; Ellis \& Witt, 1991; Neulinger, 1974) being considered to be leisure and the definitional point (external or internal) taken by the researcher. In order to get a complete picture of leisure time, we decided to include all the activities a person can do in their free time, combining both definitional points.

Free time, as opposed to time spent at work, in school or college, gives us the opportunity to autonomously choose what we want to do, who we want to spend time with, and to choose the activities we want to engage in. Those choices might reflect our life goals and motivations, as well as orientations to happiness, or our current mood, and most certainly they have an effect on our well-being. Once basic biological needs are met, leisure will most likely become a valuable source of subjective well-being, especially because it is more under individuals' control than work or school (Diener, Suh, Lucas \& Smith, 1999;

\footnotetext{
* Faculty of Humanities and Social Sciences in Rijeka, Department of Psychology

Corresponding author: Petra Anić, e-mail: panic@ffri.hr
} 
Diener \& Biswas-Diener, 2008; Newman, Tay, \& Diener, 2014). Leisure can be rewarding when intrinsically valuable pursuits allow people to use their skills and interact with friends and family (Argyle, 2001). In the research by Campbell, Converse \& Rodgers (1976), the domain most strongly related to the global index of well-being was the domain covering non-working, or spare time activities Different free time activities provide different benefits to individuals. For example, TV watching is a good way to relax, but unless one is watching a documentary, or educational program, little else can be gained from it. Therefore, the nature of leisure activities is important, particularly the question of whether they provide sufficient challenges or structure. Activities that provide sufficient challenges and require some effort and concentration are considered to have the greatest developmental value (Shaw, Kleiber, \& Caldwell, 1995), and activities that have clear goals are of the most benefit psychologically (Garst, Scheider, \& Baker, 2001).

Many studies have examined what people do in their free time, but only a small number of studies have tried to explain why people do these things. Theories of motivation are a good starting point in explaining the reasons why people engage in a particular form of activity. Many theories of motivation, amongst which is self-determination theory (Ryan \& Deci, 2000), focus on the relation of beliefs, values, and goals with action differentiating between extrinsic and intrinsic motivation. Self-determination theory claims that people have inherent growth tendencies and innate psychological needs that are necessary for self-motivation and personality integration (Ryan \& Deci, 2000). Intrinsic motivation concerns active engagement in activities or tasks that people find interesting and that promote growth. Intrinsically motivated behaviours are behaviours in which person freely engages out of interest, without need for separable consequence. To be maintained they require satisfaction of needs for autonomy, competence and sometimes relatedness (Deci \& Ryan, 2000). If a chosen activity satisfies individual's needs, he or she will continue with that activity trying to do better and better. Self-determination theory, in its application on leisure domain, focuses on examination how intrinsic motivation influences people to develop and persist (or even compete) in sports or any other chosen activity (Frederick-Recascino \& Ryan, 1993). Since intrinsic motivation is characterized by feelings of free choice, it is much more likely that a person will be intrinsically motivated during free time than at work or at school, where activities are mostly defined and imposed by others. Free time is characterized, amongst other things, by the great amount of freedom and autonomy. A person can choose what to do and at what time, with whom he or she wants to be, where to go, etc. All that autonomy makes free time ideal for satisfying our basic needs, which will, depending on how successful we are, enhance our well-being.

From the ancient history, there has been a debate about what defines optimal experience and what «good life» is. In the last several decades, the line has been drawn between two historical views of happiness and the field of studying well-being has been divided in two fairly distinct, yet overlapping, perspectives, aroused around two distinct philosophies. The first perspective, according to which well-being consists of pleasure and happiness, is labelled hedonism (Kahneman, Diener, \& Schwarz, 1999) and is mostly focused on assessment of subjective well-being. According to second perspective, well-being is not just about happiness, instead it is found in the actualization of human potentials or realizing one's true nature. This view is labelled eudaimonism (Waterman, 1993). Eudaimonia is defined as subjective experiences associated with doing what is worth doing and having what is worth having (Norton, 1976). It refers to the feelings present when individual is moving toward self-realization by development of one's unique potentials and furthering one's purpose in living (Waterman, Schwartz, \& Conti, 2008). Even though they are very different, hedonic and eudaimonic experiences can coincide: the results from many studies suggest that these two processes work in tandem.

More recently, with the expansion of positive psychology, several models and theories accentuate the role of activities in well-being by defining happiness as a positive subjective state, which is experienced to a greater degree when one is engaged in some activities rather than in others. Waterman, et al. (2008) have categorized activities by their potential to produce hedonia or eudaimonia: some of them can yield both of them, other activities can yield only hedonia or eudaimonia, while the category of activities that enhance eudaimonia without hedonia is considered as a theoretical null. When a person finds the development of personal potentials important, and when he or she is engaged in an activity that helps to realize those potentials, then both hedonic enjoyment and eudaimonia will be experienced. Different activities, or to be more precise, activities which one engages in due to different motives, can promote well-being in different ways (Huta \& Ryan, 2010). Free time gives a person the perfect opportunity to engage in an activity one really likes and wants to do, and is therefore chosen autonomously from intrinsic reasons. In this way, free time becomes one of the most important sources of well-being, considering the opportunities it provides for the satisfaction of basic psychological needs, in an individually tailored way.

Considering all the different ways of spending free time, probably the most researched single leisure activity is sport. Janssen and LeBlanc's (2010) extensive review of the studies researching the relationship between physical activity and health confirmed the numerous benefits of physical activity, with greater involvement leading to greater benefits, as well as the point that even moderately intense physical activity is enough for essential health benefits. Similar results are obtained in a review of 15 longitudinal studies: physical activity is a protective factor for the development of non-communicable (chronic) diseases (Reiner, Niermann, Jekauc, \& Woll, 2013).

Exercise and physical activity is also important for mental health. The positive effects of physical activities on psychological functioning (e.g. mood, energy) have been 
demonstrated in laboratory settings as well as in daily life (e.g. Giacobbi, Hausenblas, \& Frye, 2005; Hogan, Mata, \& Carstensen, 2013). Since exercise and physical activity are almost universally related to positive health outcomes, and a lack of physical activity is a serious public health concern, it is necessary to study the motivations behind exercising in order to develop programs for improving the physical activity of people of all ages.

During adolescence, the level of engagement in physical activities declines as adolescents get older (Caspersen, Pereira, \& Curran, 2000; Stone, McKenzie, Welk, \& Both, 1998): in high school, 65\% percent of students report participating in vigorous physical activity, compared to only $38 \%$ of college students (Douglas et al., 1997; Grunbaum et al., 2002). By adult age, more than twothirds of Americans are inactive and their physical activity is below the recommended level for health benefits, living a predominately sedentary life (Booth \& Chakravarthy, 2002). Situations in other countries, like Croatia or Brasil, are only a little better: $40-50 \%$ of the population older than 12 years is physically inactive (e.g. Greblo, Pedišić, \& Jurakić, 2008; Hallal, Victora, Wells, \& Lima, 2003). Exercising, especially regular exercise, is a complex process made up of cognitive and behavioural components, which has a high risk of encountering problems and failure (Šimunić \& Barić, 2011).

Motivation can be seen as those thoughts that coerce individuals to start doing something, some task, and regulate the direction, intensity and perseverance of specific task-related behaviours (Buckworth, Lee, Regan, Schneider, \& DiClemente, 2007). Perhaps one of the most frequently mentioned theories of motivation in this field is self-determination theory as developed by Deci and Ryan (e.g. 2000; 2008). This is a meta-theory of human motivation and personality, a theory that differentiates between intrinsic and extrinsic sources of motivation, assuming a human's inherent growth tendencies and their satisfaction of basic psychological needs. As a meta-theory, it is comprised of 6 mini-theories, developed to explain specific phenomena, addressing one facet of motivation or personality. For the purposes of the present research, Organismic Integration Theory (OIT) is the most important. It uses a continuum of internalization on which it places amotivation, four subtypes of extrinsic motivation (external regulation, introjection, identification and integration), and finishes with intrinsic motivation (Ryan \& Deci, 2000). Intrinsic motivation comes from the basic psychological needs for competence, autonomy and relatedness and is associated with self-determination, seen as a feeling of autonomy and control. People are intrinsically motivated when they do something to experience the feelings of pleasure and satisfaction during the action or process. On the other hand, extrinsically motivated behaviours have contingent outcomes, such as external reward. The purpose of these behaviours is to gain some benefits, or to avoid negative consequences. Intrinsic motivation is flexible, focused on the present task, and it doesn't depend on external reinforcers. Furthermore, extrinsic rewards might undermine intrinsic motivation, by reinforcing the external locus of control, and decreasing autonomy (Deci, Koestner, \& Ryan, 1999; Frederick-Recascino \& Ryan, 1995).

A comparison of motivation for exercise and sports revealed that exercise is primarily motivated by extrinsic factors (weight control, body image), while sports' participation is mainly motivated by intrinsic motives (competence, enjoyment) (Frederick-Recascino \& Ryan, 1993; Ryan, Frederick-Recascino, Lepes, Rubio, \& Sheldon, 1997). Similar results are obtained in the study by Kilpatrick, Hebert and Bartholomew (2005): exercise is motivated by appearance, strength, endurance, health, stress and weight management, while participation in sports is motivated by affiliation, challenge, competition, enjoyment and social recognition. However, motives might differ during the different stages of exercising: appearance and weight management motives are more important in the early stages, while enjoyment and revitalisation are more important for the progression and maintenance of the actual activity (Ingledew \& Markland, 2008).

\section{The aims of the present study}

The present research is comprised of two studies. In the first, we aimed to obtain a detailed picture of the ways in which students spend their free time. In Study 1, we were also interested in their motivation for one specific activity, the one that participants choose frequently and autonomously, and which they love. That activity was considered to be their favourite free time activity, and for that activity we tested motives for engagement. It was expected that participants engage in different activities for different motives, trying to gain different things. Results of the first study were criteria for choosing the most frequently mentioned favourite activity that should be studied in more details. Therefore, within the second study, our focus was on the motivation for exercising or recreation amongst college students. The research question of Study 2 was to investigate the differences in intrinsic motivation between recreational athletes and students who exercise only within obligatory physical education course. We presumed intrinsic motivation of recreational athletes would be higher compared to the other group of participants.

\section{Method}

\section{Study 1}

\section{Participants}

The participants were made up of 585 university students (381 females, 204 males), aged between 18 to 27 years, with a mean age of $20.58(S D=1.67)$, who completed the whole set of questionnaires. The response rate was $76 \%$. Participants were students from: Faculty of Maritime Studies $(\mathrm{N}=64)$, Faculty of Law $(\mathrm{N}=61)$, Faculty of Medicine $(\mathrm{N}=83)$, Faculty of Economics $(\mathrm{N}=99)$, Faculty of Tourism and Hospitality Management $(\mathrm{N}=71)$, Faculty of Humanities and Social Sciences $(\mathrm{N}=91)$, Faculty of Civil Engineering $(\mathrm{N}=49)$, Academy of Applied Arts $(\mathrm{N}=11)$, Faculty of Engineering $(\mathrm{N}=41)$, University Department of Informatics $(\mathrm{N}=14)$ and the Business department of Rijeka Polytechnic $(\mathrm{N}=1)$. 
What do students do in their free time and why?

\section{Instruments}

Engagement in free-time activities was assessed with a checklist constructed for this research, based on Anić and Tončić's scale (2014). Free-time activities were defined as activities that students can engage in when not in class or involved in other duties at the university. The list consisted of 10 activities, and participants could write down a further three activities that they engaged in during free time (if they were not included in the list). Participants had two tasks: to choose the activities they engaged in during their free time, and to write how many hours a week they spend doing each of them.

Motivation for the favourite activity was assessed via the Self-reported Hedonic and Eudaimonic Activities - SHEA scale (Huta, 2007). The scale has eight items divided into two subscales: eudaimonic and hedonic motives, with four items measuring hedonic (e.g., enjoying yourself; relaxing) and four items measuring eudaimonic motives (e.g., doing something you believe in; developing your potential). Every participant was asked to write down one activity in which he or she is engaged frequently and autonomously and which he or she loves. That activity was named as favourite free time activity and participants rated several eudaimonic and hedonic motives for engaging in it. Ratings are provided on a 7-point Likert type scale (1 - not at all to 7 - very much). Principal axis factor analysis confirmed the two-factor solution (eigenvalues before rotation were $3.81,1.88,0.59$ and 0.46 ). The two factors accounted for $62.11 \%$ of the variance. The data were oblimin rotated. Every item loaded more highly on the factor it was intended to measure. Cronbach alpha for eudaimonic motives was .87 and for hedonic .85 , showing adequate internal consistency. Correlation between factors is .36. The final factor structure is shown in Table 1 .

\section{Procedure}

The research was conducted over a period of three months during 2013/2014 academic year. Researchers contacted potential participants via their course professors, and pointed out that participation was voluntary and anonymous. Researcher explained the theme and nature of study and the ways of ratings are to be made. All questionnaires were administered together. It took approximately 40 minutes to complete the questionnaires.

\section{Data analysis}

The SPSS 21 software package was used for all statistical analyses. Before analyzing data, exploratory factor analysis was done for SHEA scale. For the first part of the analysis, descriptive data for free time activities was provided to give information about typical ways of spending free time, and the amount of time spent in each activity. Next, descriptive data was also given about the motives of engaging in a favourite leisure activity. Participants were classified into three clusters according to their motivation for the activity, which were then compared for different activities.

\section{Results and discussion}

Participants chose those free time activities they engaged in from a list of 10 activities and estimated the hours per week that they spent doing each of the selected activities. Due to the possible overestimation of hours left to engage in free time activities, which was confirmed by an inspection of the results, we did some calculations to determine the maximum time left for free time activities. To determine the maximum hours that could be spent doing these activities, time for sleeping and time for travel,

Table 1. Results of principal axis factor analysis with oblimin rotation for Self-reported Hedonic and Eudaimonic Activities questionnaire $(\mathbf{N}=\mathbf{5 8 5})$

\begin{tabular}{|c|c|c|c|c|}
\hline \multirow{2}{*}{ Factor } & \multirow{2}{*}{ Item } & \multicolumn{2}{|c|}{ Factor loadings } & \multirow{2}{*}{$\mathbf{h}^{2}$} \\
\hline & & $\mathbf{F 1}$ & F2 & \\
\hline \multirow{4}{*}{$\begin{array}{l}\text { Eudaimonic } \\
\text { motives }\end{array}$} & developing your potential & .94 & -.11 & .82 \\
\hline & pursuing excellence or personal ideal & .82 & .00 & .67 \\
\hline & developing a skill, learning, or gaining insight into something & .76 & .00 & .57 \\
\hline & doing something you believe in & .64 & .16 & .51 \\
\hline \multirow{4}{*}{ Hedonic motives } & enjoying yourself & -.07 & .91 & .79 \\
\hline & relaxing & -.06 & .75 & .53 \\
\hline & being entertained & .03 & .69 & .49 \\
\hline & experiencing pleasure & .20 & .67 & .59 \\
\hline Eigenvalue $^{1}$ & & 3.81 & 1.88 & \\
\hline Pct of variance ${ }^{1}$ & & 47.53 & 23.52 & \\
\hline Eigenvalue $^{2}$ & & 2.55 & 2.37 & \\
\hline Pct of variance ${ }^{2}$ & & 32.23 & 29.89 & \\
\hline
\end{tabular}

Note. ${ }^{1}$ before rotation; ${ }^{2}$ after rotation 
personal maintenance (e.g. eating, taking a shower) and minor household jobs had to be subtracted from the 168 (hours in a week). In this research, participants were not asked to estimate the number of hours of sleep they had per day or week. Instead, we employed the findings of Tkalčić and Lončarić's (1998) research, conducted on a sample of students from the University of Rijeka. According to this research, students sleep approximately 8 hours per day. The amount of time spent on travel, maintenance and household activities was estimated based on data from three studies on adolescents' and students' use of time (Bassi \& Delle Fave, 2004; Delle Fave \& Bassi, 2000; Duckett, Rafaelli, \& Richards, 1989). The weighted mean was calculated and used as an estimation of how much time participants spend on travel, maintenance and household activities. Based on this calculation, participants spend $22.74 \%$ of their waking hours on these activities. The final result, after subtracting time for sleeping, travel, maintenance and household activities, is 86.45 hours per week, which is available for engagement in different activities. For participants who stated to spend more than 86.45 hours per week on free time activities, the following correction for overestimation was conducted: time spent in each of activities was linearly decreased according to the proportion of that activity in total weekly free time. Specifically, proportions in total weekly free time were first computed for each activity and then multiplied by 86.45 hours, which we calculated was the maximum time that individual can spend on leisure weekly. For example, if participant stated to spend 40 hours on reading, 35 hours on studying and 30 hours per week on social interactions (a total of 105 hours), corrected values would equal $32.93[(40 /(40+35+30) \times 86.45], 28.82$ and 24.70 hours per week, respectively (a total of 86.45 hours).

During this time ( 86.45 hours), participants go to classes, while the remaining time is considered to be free time. Time spent in classes was not excluded because the differences between different faculties and study groups, as well as between individuals, is too great to generalize. Instead, participants were asked how they spend their free time, when they are not at the faculty. Descriptive data for participants that practice particular activities are shown in Table 2.

Table 2 shows that there are great differences in the percentages of participants who engage in different activities. The smallest percentage of participants engages in artistic activities and volunteering, while the largest percentage of participants reads, spends time with their family and studies. Reading was the most frequently chosen way of spending free time. In this study, no differentiation was made as to what students were reading: newspapers, magazines, novels, or some faculty related literature. Since there was a category of free time related to studying and doing any other form of work for the faculty, it is assumed that the category "Reading" was perceived as reading something else, something not related to their studies. Larson and Verma (1999) categorized reading as a part of the "Media use" category and found that it is the second most endorsed activity in this category, after TV watching, and that adolescents engage in it approximately 33 minutes a day. Most participants enrolled in current studies read 5 hours a week (the median is reported, because of the large skewness of this variable), which is quite similar to the 33 minutes per day in Larson and Verma's study (1999).

The next most frequent free time activity is leisure with family. Participants were not asked what do they do with their family members (do they engage in an active activity, like playing music or chess together, going for a walk and similar, or do they simply watch TV together). Therefore, we cannot comment on this type of free time activity in detail. We would like to draw attention to a possible source of confusion here. A well-known fact is that during adolescence, time spent with families' decreases, while time spent with peers' increases (e.g. Zeijl, Du Bois-Reymond, \& Te Poel, 2001) and it stays like that

Table 2. The percentages of participants who engage in different activities and descriptive statistics of hours per week spent in different activities $(\mathbf{N}=\mathbf{5 8 5})$

\begin{tabular}{lcrrrrr}
\hline \multirow{2}{*}{ Activities } & \% & \multicolumn{2}{c}{ Range } & \multicolumn{2}{c}{ Central tendency } & SD \\
\cline { 3 - 5 } & & Min & Max & Mean & Median & \\
\hline Reading & 63.59 & 0.35 & 72.00 & 6.38 & 5.00 & 7.33 \\
Leisure with family & 60.17 & 0.50 & 86.45 & 16.46 & 11.36 & 14.30 \\
Studying & 58.63 & 1.50 & 86.45 & 22.71 & 20.00 & 14.89 \\
Social interactions & 48.71 & 2.50 & 79.76 & 30.19 & 27.00 & 17.43 \\
\hline Sports & 32.48 & 0.35 & 39.30 & 5.48 & 4.00 & 5.17 \\
Shopping & 29.57 & 0.24 & 20.00 & 2.62 & 2.00 & 2.70 \\
\hline Travelling, hiking & 18.29 & 0.47 & 24.00 & 4.52 & 3.00 & 4.26 \\
Electronic media, TV & 15.90 & 0.50 & 45.22 & 13.88 & 12.35 & 8.66 \\
Volunteering & 3.59 & 0.50 & 11.04 & 2.21 & 1.50 & 2.30 \\
Artistic activities & 0.85 & 2.88 & 9.00 & 5.44 & 5.66 & 2.31 \\
\hline
\end{tabular}


through early adulthood. Considering this, the described result might seem contra intuitive. However, only the frequency of students who spend time with their families is commented on here. If attention is paid to the amount of time spent with family members and the amount of time spent in social interactions with friends, it can be seen that much more time is spent with friends. This is coupled with the finding that in adolescence the ratio of time spent with family and peers changes in favour of time spent with peers, and it remains like this also as people get older.

Studying is also a frequently reported activity. It was expected that many participants would report that they study in their free time, because their curriculums are quite demanding where they need to do a lot of assignments at home. A similar finding is the one of Delle Fave and Bassi (2000), who found that among Italian adolescents, studying at home is the most frequently reported activity.

The amount of time students spend in particular activities shows that social interactions and studying are the activities in which students spend most of their free time. In social interactions, students on average spend around 30 hours per week, which is approximately $35 \%$ of their weekly free time. In the most recent study done on student samples in Croatia, Bouillet, Illišin, and Potočnik (2008) compared students' free time activities in 1999 and 2004. In both measurements, the three most frequently endorsed activities were socializing with friends, watching TV and videos, and going to bars and cafés. In the present research, socializing with friends and going out is combined into one category, and therefore it can be concluded that our results are similar to theirs. The difference is in the electronic media and TV category, which our students engage in somewhat less (it is on 4th place, after leisure with family).

As for time spent studying, students in this current research reported that on average they study or do some faculty related assignments approximately 23 hours per week. According to Eurostudent data collected in 2010 (Cvitan, Doolan, Farnell, \& Matković, 2011), the greatest number of students $(59 \%)$ spend over 30 hours attending lectures or learning. Out of those hours, 17.5 hours are spent on lectures and 15.4 on learning. Therefore, the current study's data are not similar to Eurostudent's data: students in the current study spend much more time learning, writing and preparing for classes than students enrolled in Eurostudent research. This difference could perhaps be attributed to the fact that in our study only students attending the University of Rijeka were included, whilst the Eurostudent study was carried out at all universities in Croatia. The University of Rijeka, in comparison with other universities in Croatia, has a different set of regulations about how students study, which might be the reason for the different amounts of time spent on learning, writing and preparing for classes at home. Students at the University of Rijeka get $70 \%$ of their final grade from work and assignments during the semester, and a large portion of that work is done at home (e.g. writing seminars, reports, learning, etc.). Therefore they need to do more faculty related work at home than students from other universities.

The second part of the first study was orientated towards studying the motivation for leisure activities. All participants stated their favourite activity - an activity they have freely chosen, that they love and enjoy. Two independent investigators, familiar with the research domain, constructed categories, compared and matched them and then the activities were categorized based on their similarity. Similar activities were grouped together (e.g. all sport activities were grouped in the same category, all activities related to computers, music or TV are grouped in one category, etc.). Cohen's Kappa index indicated good inter-rater agreement (.86). Activities that were only mentioned as favourites more than a few times were excluded based on the premise that they are not typical for students. This resulted in four categories of activities: media, art, physical and social activities.

Participants rated their favourite activity on several questions reflecting the hedonic and eudaimonic motives for engaging in it. In this way, mean scores of hedonic motives and mean scores of eudaimonic motives for each of the four favourite activity categories were obtained.

As it was expected that participants engage in different activities for different motives, where they try to gain different things, the differences between motives for different activities were tested. The descriptive data and the results of analysis are shown in Table 3.

The average ratings of eudaimonic motives for different favourite activities are more dispersed than the average ratings of hedonic motives.

Table 3. Descriptive statistics and differences of eudaimonic and hedonic motives for different activities $(\mathrm{N}=585)$

\begin{tabular}{lcccccc}
\hline \multirow{2}{*}{ Activities } & $\mathbf{N}$ & \multicolumn{2}{c}{ Eudaimonic motives } & \multicolumn{2}{c}{ Hedonic motives } & \multirow{2}{*}{ t-value } \\
\cline { 3 - 6 } & & $\mathbf{M}$ & SD & $\mathbf{M}$ & $\mathbf{S D}$ & \\
\hline 1. Physical activities & 298 & $5.61_{2,3}$ & 1.17 & 6.36 & 0.71 & $11.86^{* *}$ \\
\hline 2. Media use & 136 & $5.13_{1,3,4}$ & 1.55 & 6.37 & 0.76 & $9.61^{* *}$ \\
\hline 3. Socializing & 90 & $5.48_{1,2,4}$ & 1.27 & 6.50 & 0.64 & $10.72^{* *}$ \\
\hline 4. Artistic activities & 61 & $6.12_{2,3}$ & 0.97 & 6.48 & 0.73 & $4.06^{* *}$ \\
\hline F-value (df) & & $12.94^{* *}$ & $(3.579)$ & 1.38 & $(3.578)$ & \\
\hline
\end{tabular}

Note. $\mathrm{M}-$ mean; $\mathrm{SD}$ - standard deviation; ${ }^{* *} \mathrm{p}<.01 ; \quad$ Indexed numbers, show significant differences, according to Tukey post-hoc test 
It was hypothesized that people engage in different activities for different motives, pursuing different goals, and trying to gain different benefits from the activity. From Table 3, it can be seen that the means of the hedonic motives are somewhat higher than the means of the eudaimonic motives for all activities, which suggests that the hedonic motives might be more important activity motivators than the eudaimonic. Overall, eudaimonic motives vary more than hedonic, showing that free time activities are a good way to obtain hedonic gains, or pleasure and satisfaction, but only some activities will produce a sense of eudaimonia. All activities are approximately equally hedonically motivated, suggesting that no matter what the favourite activity is, the enjoyment and pleasure experienced are about the same. As for eudaimonic motivation, activities differ: artistic activities and physical activities are higher on eudaimonic motives than media and socializing, while socializing is more eudaimonically motivated than activities related to media use. However, the differences between means are so small that their practical importance is quite questionable. According to eudaimonic models of happiness (e.g. Huta \& Ryan, 2010; Waterman, 1993), in order to be happy one needs to live a life worth living, engaging in meaningful activities. It looks like artistic and physical activities provide more opportunities for personal development, engagement and meaning than socializing or media activities.

In an attempt to test the premise of Waterman et al. (2008), that there are three possible combinations of motives for activities: high hedonia and eudaimonia, high hedonia and low eudaimonia and low hedonia and eudaimonia, with the fourth category of activities giving rise to eudamonia but not hedonia being theoretically impossible, we applied cluster analysis on standardized scores of hedonic and eudaimonic motives. In the first step, the hierarchical cluster analysis was used (Ward's method) to identify the right number of clusters. The results strongly suggested three clusters solution as optimal. In the second step, by using K-mean clustering on the centroids the final cluster solution was obtained. The results of final cluster analysis are shown in Tables 4 and 5.

Participants are classified into three groups: group with high eudaimonic and hedonic motives, group with low eudaimonic and hedonic motives, and group with low eudaimonic and high hedonic motives. The obtained clusters differed significantly in motivation for the favourite leisure activity: hedonic motives, $\mathrm{F}_{2,582}=2254.43, \mathrm{p}<.001$; eudaimonic motives, $\mathrm{F}_{2,582}=214.80, \mathrm{p}<.001$.

If we look at the raw scores, and test for the differences, we can see that groups differ one from another on the hedonic $\left(\mathrm{F}_{2,582}=353.81, \mathrm{p}<.01\right)$ and eudaimonic motives $\left(\mathrm{F}_{2,582}=595.34, \mathrm{p}<.01\right)$. Post-hoc comparisons (Tukey HSD) revealed significant differences between all groups.

It is interesting to compare standardized cluster means and raw means. Inspection of the raw scores reveals that in the first group, raw mean of motives really are above theoretical scale mean, which is 3.5, just like standardized means are. But, the same is true for the second group, the one with standardized scores for both motives below mean. This means that participants in this group rate their motives
Table 4. Final cluster centers $(\mathbf{N}=\mathbf{5 8 5})$

\begin{tabular}{lccc}
\hline & \multicolumn{3}{c}{ Cluster } \\
\cline { 2 - 4 } & $\begin{array}{c}\mathbf{E}+\mathbf{H}+ \\
\mathbf{N}=\mathbf{3 7 6}\end{array}$ & $\begin{array}{c}\mathbf{E}-\mathbf{H}- \\
\mathbf{N}=\mathbf{1 4 9}\end{array}$ & $\begin{array}{c}\mathbf{E}-\mathbf{H}+ \\
\mathbf{N}=\mathbf{6 0}\end{array}$ \\
\hline Eudaimonic motivation & 1.01 & -1.10 & -3.83 \\
\hline Hedonic motivation & 0.96 & -0.22 & 0.64 \\
\hline
\end{tabular}

Note. Groups: $\mathrm{E}+\mathrm{H}+$ (both motives above average); E-H- (both motives below average); E-H+ (eudaimonic motives below average, hedonic above).

Table 5. Average standardized scores and mean scores on clusters of motivation for favourite leisure activity $(\mathrm{N}=\mathbf{5 8 5})$

\begin{tabular}{lccc}
\hline & \multicolumn{3}{c}{ Cluster } \\
\cline { 2 - 4 } & $\begin{array}{c}\mathbf{E}+\mathbf{H}+ \\
\mathbf{N}=\mathbf{3 7 6}\end{array}$ & $\begin{array}{c}\mathbf{E}-\mathbf{H}- \\
\mathbf{N}=\mathbf{1 4 9}\end{array}$ & $\begin{array}{c}\mathbf{E}-\mathbf{H}+ \\
\mathbf{N}=\mathbf{6 0}\end{array}$ \\
\hline \multirow{2}{*}{ Eudaimonic motivation } & 0.50 & -0.48 & -2.08 \\
& $(6.14)$ & $(4.88)$ & $(2.85)$ \\
\hline \multirow{2}{*}{ Hedonic motivation } & 0.52 & -1.04 & 0.17 \\
& $(6.74)$ & $(5.50)$ & $(6.46)$ \\
\hline
\end{tabular}

Note. Groups: $\mathrm{E}+\mathrm{H}+$ (both motives above average); E-H- (both motives below average); $\mathrm{E}-\mathrm{H}+$ (eudaimonic motives below average, hedonic slightly above). Mean scores are shown in parentheses.

above scale mean, but still they are less motivated than others. Finally, in the third group are participants with raw scores quite below average on eudaimonic motivation and above theoretical mean on hedonic motivation, which is similar to the pattern seen from standardized scores.

The number of participants in each cluster offer some potentially interesting information. The highest number of participants is classified in the group characterized by the above average of both eudaimonic and hedonic motives, while the smallest number of participants is in the group with really low eudaimonic and rather high hedonic motives. This is in accordance with our expectation that mainly hedonic, and to some extent even eudaimonic motives will be satisfied through the favourite leisure activity. Crosstabulation of activities and motives' groups offers more details on the relationship between motives and activities. The results of this analysis are shown in Table 6 .

The number of participants with a particular motives' profile differs throughout the three categories of activities: $\chi^{2}=26.01, \mathrm{df}=6, \mathrm{p}<0.01$. Participants with above average eudaimonic and hedonic motives engage in media use related activities less than expected, but they engage in artistic activities more than expected. Participants within profile characterized by below average eudaimonic and above average hedonic motivation engage more than what was expected in those activities related to media use, but less than what was expected in artistic and physical activities.

Activities that give rise to eudaimonia are a source of hedonic enjoyment as well, but the reverse is not always 
What do students do in their free time and why?

Table 6. Frequencies of leisure activities and profiles of motives for leisure activity $(\mathrm{N}=\mathbf{5 8 5})$

\begin{tabular}{lccc}
\hline \multirow{2}{*}{ Activities } & \multicolumn{3}{c}{$\begin{array}{c}\text { Groups of different profiles } \\
\text { of motives for leisure activity }\end{array}$} \\
\cline { 2 - 4 } & $\mathbf{E}+\mathbf{H}+$ & E-H- & E-H+ \\
\hline Media use & 73 & 36 & 27 \\
& $(-2.9)$ & $(0.3)$ & $(4.2)$ \\
\hline \multirow{2}{*}{ Artistic activities } & 48 & 12 & 1 \\
& $(2.5)$ & $(-1.1)$ & $(-2.3)$ \\
\hline \multirow{2}{*}{ Physical activities } & 196 & 81 & 21 \\
\hline \multirow{2}{*}{ Socializing } & $(0.8)$ & $(1.0)$ & $(-2.6)$ \\
\hline & 59 & 20 & 11 \\
& $(0.3)$ & $(-0.8)$ & $(0.7)$ \\
\hline
\end{tabular}

Note. Adjusted standardized residuals are shown in parentheses.

true - hedonic enjoyment does not have to be accompanied by eudaimonia (Waterman et al., 2008). Our results confirm this notion, as well as the notion that eudaimonia without hedonia is theoretical null (Waterman et al., 2008): we haven't obtain a category where eudaimonic motives for activities are above average and hedonia is below average. Perhaps this is because we examined only favourite activities, which might be more relaxing and pleasurable than other activities. Maybe, if we asked participants to rate some organized activity that they engage in on regular basis, we would obtain a group of participants who are mainly eudaimonically motivated. For example, enrollment in school of foreign languages - a person might be eudaimonically motivated, because he or she learns new things, but the hedonic motivation might be low, because the course might be demanding with little opportunities for experiencing pleasure.

\section{Study 2}

\section{Method}

\section{Participants}

The participants were made up of 202 first-year undergraduate university students, 167 females and 35 males, none of whom participated in Study 1. All of them attended the Faculty of Humanities and Social Sciences. The age range of the participants was 18-27 years $(\mathrm{M}=19.41 ; \mathrm{SD}=1.43)$, and all of them were enrolled on an obligatory physical education course. Within this course, they had to participate in their chosen sport activity. These exercise sessions took place one hour per week over the first two semesters.

\section{Instruments}

Intrinsic motivation for physical activity was assessed via the Intrinsic motivation inventory - IMI (McAuley, Duncan \& Tammen, 1989). This multi-dimensional inventory contains 18 items measuring four dimensions of intrinsic motivation, where ratings are given on a 5-point Likert type scale $(1-$ yes to 5 - no). Perceived competence (e.g. I think I am pretty good at exercising.), interestenjoyment (e.g. Exercising is fun.) and effort-importance (e.g. I put a lot of effort into exercising.) are positive predictors of intrinsic motivation, while tension-pressure (e.g. I felt very tense while exercising.) is a negative predictor. The sport-oriented Croatian version of IMI (Barić, Cecić-Erpič \& Babić, 2002) was applied in the present study. Internal consistency for all four components was adequate. Cronbach's alpha coefficients ranged from .80 to .85 (Table 7 ).

In order to collect information about age, sex and physical activity, IMI was accompanied with a short demographic questionnaire.

Table 7. Inter-correlations (Pearson's r coefficients) and reliability coefficients of IMI subscales $(N=192)$

\begin{tabular}{|c|c|c|c|c|c|}
\hline IMI subscale & 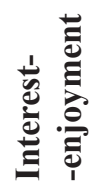 & 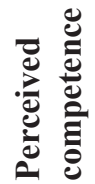 & 递 & 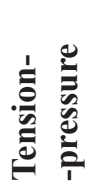 & 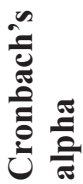 \\
\hline
\end{tabular}

Interest-

-enjoyment

.83

\begin{tabular}{lccccc}
\hline $\begin{array}{l}\text { Perceived } \\
\text { competence }\end{array}$ & $.79^{* *}$ & - & & .85 \\
\hline $\begin{array}{l}\text { Effort- } \\
\text {-importance }\end{array}$ & $.71^{* *}$ & $.71^{* *}$ & - & .85 \\
\hline Tension-pressure & $-.47^{* *}$ & $-.46^{* *}$ & $-.40^{* *}$ & - & .80 \\
\hline${ }^{* *} \mathrm{p}<.01$ & & & & &
\end{tabular}

\section{Procedure}

Data was collected at the beginning of the second semester of 2014/2015 via traditional pen and paper method, with no time limit. All first-year undergraduate students of the Faculty of Humanities and Social Sciences $(\mathrm{N}=480)$ were invited to participate in the study and were informed that participation was voluntary and that their responses would be confidential. Response rate was $42.08 \%$.

\section{Data analysis}

Statistical analyses were conducted in the SPSS 21 software package. After the missing data analysis and replacement, exploratory factor analysis was conducted. In order to test differences in intrinsic motivation between participants who exercised only within obligatory physical education course and participants who exercised at least once a week on a regular basis in addition to the obligatory physical education course, t-test was applied.

\section{Results and discussion}

Only 174 of 202 participants completed the entire IMI questionnaire without any missing values. For the remaining 28 participants, missing data analysis was conducted, and it was found that 18 participants have no more than one missing value across any of the four IMI 
Table 8. Means, standard deviations, number of items, skewness and kurtosis indices for four IMI subscales $(\mathrm{N}=192)$

\begin{tabular}{|c|c|c|c|c|c|c|c|}
\hline IMI subscale & Activity & $\mathbf{N}$ & $\mathbf{M}$ & SD & Items & Skewness (standardized) & Kurtosis (standardized) \\
\hline \multirow{2}{*}{$\begin{array}{l}\text { Perceived } \\
\text { competence }\end{array}$} & Low $^{*}$ & 83 & 3.04 & 0.86 & \multirow{2}{*}{5} & $-0.63(-2.39)$ & $0.35(0.67)$ \\
\hline & High $^{* *}$ & 109 & 3.69 & 0.72 & & $-0.66(-2.86)$ & $1.42(2.90)$ \\
\hline \multirow{2}{*}{$\begin{array}{l}\text { Interest- } \\
\text { enjoyment }\end{array}$} & Low $^{*}$ & 83 & 2.88 & 0.91 & \multirow{2}{*}{5} & $-0.41(-1.55)$ & $-0.34(-0.65)$ \\
\hline & High $^{* *}$ & 109 & 3.37 & 0.84 & & $-0.32(-1.39)$ & $-0.17(-0.37)$ \\
\hline \multirow{2}{*}{$\begin{array}{l}\text { Effort- } \\
\text { importance }\end{array}$} & Low* & 83 & 2.99 & 0.95 & \multirow{2}{*}{4} & $-0.48(-1.81)$ & $-0.34(-0.65)$ \\
\hline & High $^{* *}$ & 109 & 3.66 & 0.84 & & $-0.49(-1.69)$ & $-0.01(-0.02)$ \\
\hline \multirow{2}{*}{$\begin{array}{l}\text { Tension- } \\
\text { pressure }\end{array}$} & Low $^{*}$ & 83 & 2.66 & 0.88 & \multirow{2}{*}{4} & $0.30(1.14)$ & $-0.29(-0.55)$ \\
\hline & High $^{* *}$ & 109 & 2.24 & 0.71 & & $0.86(3.72)$ & $1.47(3.20)$ \\
\hline
\end{tabular}

Note. *Low - group of participants who exercise only within the obligatory physical education course; ${ }^{* *}$ High - group of participants who regularly exercise at least one a week in addition to the obligatory physical education course

subscales. For these participants, mean values of remaining items within a belonging subscale were computed and inserted into datafile instead of the missing values. A total of 22 missing values were replaced across the 18 participants, following the procedure described above. Participants with more than one missing value within at least one IMI subscale were excluded, so the subsequent analyses were conducted on 192 participants (4.95\% of the sample was excluded). Descriptive data regarding the IMI subscales are presented in Table 8.

As shown earlier in Table 7, correlations between IMI subscales were high, so in order to examine the structure of IMI, exploratory factor analysis was conducted. Although four eigen-values were higher than $1(8.18 ; 2.08 ; 1.26$; 1.04 ), according to the scree-plot criterion, one-factor solution was selected. In conformity with that selection, Cronbach's alpha calculated on all 18 IMI items (after recoding the required items) was very high, it equaled .93 . Furthermore, one factor explained $45.63 \%$ of variance, while factors 2,3 and 4 managed to explain only $11.57 \%$, $6.98 \%$ and $5.77 \%$ of variance, respectively. Therefore, in the following inferential analysis, IMI was considered as one-factor scale measuring intrinsic motivation, comprised as simple linear combination of all 18 items. Results of exploratory factor analysis conducted on 18 IMI items is presented in Table 9.

Table 9. Results of exploratory factor analysis (one-factor extraction with no rotation) for Intrinsic Motivation Inventory $(\mathrm{N}=192)$

\begin{tabular}{|c|c|c|c|}
\hline Expected factor & Item & F1 load & $\mathbf{h}^{2}$ \\
\hline \multirow{5}{*}{ Interest-enjoyment } & I enjoy exercising very much. & .81 & .66 \\
\hline & Exercising is fun. & .81 & .65 \\
\hline & I would describe exercising as very interesting. & .71 & .51 \\
\hline & While I was exercising, I was thinking about how much I enjoyed it. & .48 & .23 \\
\hline & Exercising did not hold my attention at all. (R) & .58 & .33 \\
\hline \multirow{5}{*}{$\begin{array}{l}\text { Perceived } \\
\text { competence }\end{array}$} & I think I am pretty good at exercising. & .74 & .56 \\
\hline & I am satisfied with my exercise performance. & .76 & .58 \\
\hline & After exercising for a while, I felt pretty competent. & .64 & .40 \\
\hline & I was pretty skilled at exercising. & .81 & .65 \\
\hline & Exercising was an activity that I couldn't do very well. (R) & .54 & .29 \\
\hline \multirow{4}{*}{ Effort-importance } & I put a lot of effort into exercising. & .76 & .57 \\
\hline & It is important to me to do well at exercising. & .67 & .45 \\
\hline & I tried very hard at exercising. & .74 & .55 \\
\hline & I didn't try very hard to do well at exercising. (R) & .59 & .35 \\
\hline \multirow{4}{*}{ Tension-pressure } & I felt very tense while exercising. (R) & .27 & .07 \\
\hline & I felt pressured while exercising. (R) & .38 & .15 \\
\hline & I did not feel nervous at all while exercising. & .42 & .18 \\
\hline & I was very relaxed in exercising. & .73 & .54 \\
\hline
\end{tabular}


Participants were divided into two groups according to their physical activity status. The first group was comprised of 83 students who exercised only as a part of their obligatory physical education course. Participants who exercised at least once a week on a regular basis, in addition to the obligatory physical education course, were allocated to the group of recreational athletes $(\mathrm{N}=109)$. Descriptive values for intrinsic motivation factor of these two groups are presented in Table 10.

Table 10. Means, standard deviations, number of items, skewness and kurtosis indices for intrinsic motivation factor $(\mathrm{N}=192)$

\begin{tabular}{|c|c|c|c|c|}
\hline Activity & $\mathbf{N}$ & $\mathbf{M}$ & SD & $\begin{array}{c}\text { Skewness } \\
\text { (standardized) }\end{array} \begin{array}{c}\text { Kurtosis } \\
\text { (standardized) }\end{array}$ \\
\hline
\end{tabular}

\begin{tabular}{lrrrrr}
\hline Low $^{*}$ & 83 & 3.05 & 0.74 & $-0.37(-1.39)$ & $0.45(0.86)$ \\
\hline High $^{* *}$ & 109 & 3.61 & 0.64 & $-0.64(-2.79)$ & $1.44(3.13)$
\end{tabular}

Note. ${ }^{*}$ Low - group of participants who exercise only within the obligatory physical education course; ${ }^{* *}$ High - group of participants who regularly exercise at least one a week in addition to the obligatory physical education course

In order to inspect if the two groups of participants differ on intrinsic motivation, independent samples t-test was conducted. Since standardized skewness and kurtosis were not within -2 and 2 interval, Kolmogorov-Smirnov test was conducted prior to t-test, in order to inspect the normality of distribution. K-S test was not significant neither for the group of participants who exercise only within the obligatory physical education course $(K-S Z=.68 ; p>.05)$, nor for the group of recreational athletes $(\mathrm{K}-\mathrm{S} \mathrm{Z}=.62 ; \mathrm{p}>.05)$. T-test $\left(\mathrm{t}_{1,190}=5.57 ; \mathrm{p}<.001\right.$; Cohen's $\left.d=.81\right)$ revealed that recreational athletes $(\mathrm{M}=3.61, \mathrm{SD}=0.64)$ have significantly higher intrinsic motivation compared to participants who exercised only within obligatory physical education course $(\mathrm{M}=3.05, \mathrm{SD}=0.74)$. Levene's test for equality of variances was not significant $(\mathrm{F}=.82 ; \mathrm{p}>.05)$.

These results are in accordance with findings of other similar studies. For example, Cvenić, Nagy and Šmit (2014), who conducted a similar study on a sample of primary school children (age range 11-15), found that children who regularly attend sport activities differ from those pupils who exercise only within obligatory school classes: recreational athletes scored significantly higher on perceived competence and effort-importance than inactive subjects. However, no differences between the groups were found regarding the other two factors, probably because the small sample size. Furthermore, Barić, Vlašić and Cecić-Erpič (2014) discovered a high positive correlation of perceived competence with interest and enjoyment in physical education classes. Within the same study, children who scored highly on the perceived competence factor engaged in sport classes with more effort than less competent children. Perceived (athletic) competence (Fox \& Corbin, 1989) is, along with some other factors, such as goal orientations or intrinsic motivation in general, an important determinant of persistence in sports, as well as an important factor in determining interest in physical education (Cury et al., 1996).

\section{General discussion}

Free time gives us a great opportunity for identity exploration, especially in the early stages of life, when future-life choices and decisions are being made (Shaw et al., 1995). In this paper, free time activities have been researched in two ways. In a general way, where participants were asked to indicate what they do in their free time, and for how many hours a week they do it, and a specific way, where every participant stated her or his favourite activity and rated it on several items related to motives for doing it. The first way was used to get a broader picture of what students do in their free time and to see how their typical week looks like. The favourite activity was also used, because it is assumed that some of the activities in free time might not be completely freely chosen (e.g. studying), or might be a product of boredom, or "nothing else to do" (e.g. time spent with family members). However, the favourite activity, the one among the many free time activities that one engages in during the week, should be completely freely chosen by an individual. Therefore, this activity is the best for researching motives for engagement.

It is interesting to compare activities that are stated as favourite activities with activities in free time as proposed by the researcher (the ones described earlier). As can be seen, there are some similarities, and some differences. The presented results confirm a great diversity of free time activities, and point to the need to precisely specify the study goal in order to find the best research method. Some activities, like sleeping, personal maintenance or housework (cleaning, cooking), are not leisure according to the criteria by Larson and Verma (1999), and other activities, like studying, are not subjectively seen as leisure (Iso-Ahola, 1999; Neulinger, 1974). However, they still take a lot of time during a typical students' day and if one wants to get a complete picture of free time, they shouldn't be omitted. Another interesting comparison considers artistic activities: in the check-list provided by authors, only five participants stated that they are engaged in any sort of artistic activities. On the other hand, in the favourite activity study, 61 students wrote down some form of artistic activity as their favourite activity. The reason might be found in the perception of the importance of the artistic activities: maybe they are seen as really important, and favourite, but they do not occur that often, so students didn't state them while giving an approximation of the leisure activities they engage in during a typical week.

Certainly, an analysis of hedonic and eudaimonic motives for activities is not the usual way of studying motivation. However, we decided to use this approach because it can be applied to all activities, and because it allows us to see subjects' perception of motives attached to each activity. This approach can be related to more common divisions on intrinsic and extrinsic motivation through 
the already mentioned Waterman's model of well-being (e.g. Waterman, 1993; Waterman et al., 2008). There are activities that are autonomously chosen and motivated by the hedonic pleasures they provide, and intrinsically (in the narrower sense) motivated activities with two sources of motivation: hedonic pleasure and eudaimonia.

In the second study, we used a more standard approach, and researched differences in motivation for exercise between recreational athletes and participants who exercised only within obligatory physical education course. The obtained results are in accordance with findings in the literature. As expected, more active students are more intrinsically motivated, or to be more precise, they perceive themselves as more competent, are ready to invest more effort, are more interested in and enjoy exercising more than less active students. However, if we look at the means of intrinsic motivation, we can see that not even active participants are highly intrinsically motivated $(\mathrm{M}=3.61$, with possible maximum being 5.00$)$. Major satisfactions related with intrinsically motivated behaviours are experiences of competence and enjoyment (e.g. Cszikszentmihalyi \& Rathunde, 1993; Deci \& Ryan, 1985), true also in the area of sports and exercising (Rottensteiner, Tolvanen, Laakso, \& Konttinen, 2015; Yan, Berger, Tobar, \& Cardinal, 2014). Perhaps participants in the present study do not enjoy their exercising that much and are not highly intrinsically motivated because they exercise to lose weight or to maintain good looks, and people who exercise for non-appearance reasons enjoy exercising more than those who exercise for appearance based reasons (Yan et al., 2014). This seems as a plausible explanation especially if we take into account the fact that we had mostly women in our sample, and women report more often to exercise for weight loss and toning than men (Craft, Carroll, \& Lustyk, 2014). In a present research we haven't studied exact motives for exercise, but instead we concentrated only on general motivation. Therefore, above given explanations remain in the field of speculation, but they would surely be an interesting research questions for future studies.

\section{Study limitations and directions for future research}

Besides going into more details on the motives for exercising, there are many ways in which the present research could be improved. First of all, the sample in the second study is rather small, and unbalanced according to gender, which made some comparisons impossible. For example, it would be interesting to compare participants who actively practice some form of sport, with those who exercise recreationally, since the literature suggests that motives for the two activities are different. A second limitation relates to the activities offered in the check-list of free time activities. The list is not complete, and bearing in mind the variety of free time activities, it is hard to believe that it ever will be. Perhaps qualitative research, in which participants write down the activities they engage in, would be better.

\section{Conclusions}

Study 1 was focused on obtaining an overall picture about ways in which students spend free time, and to investigate motivation for engaging in favourite activity. Majority of participants spend their free time on reading $(63.59 \%)$, leisure with family $(60.17 \%)$, studying (58.63\%), social interactions $(48.71 \%)$ and sports $(32.48 \%)$. We found no significant differences in hedonic motives for free time activities, while eudaimonic motives did differ: artistic and physical activities were higher on eudaimonic motives than media and socializing. Furthermore, socializing was more eudaimonically motivated than activities related to media use. However, all these differences are rather small and their practical importance is questionable.

In the second part of Study 1, students were asked to identify their favourite activity. Since most of them reported physical activities as their favourite ones, in Study 2 we investigated intrinsic motivation for physical exercising and found that intrinsic motivation of recreational athletes was significantly higher compared to participants who exercised only within obligatory physical education course.

\section{References}

Anić, P., \& Tončić, M. (2014). "What are you doing?”: Comparison of three methodological approaches to studying leisure. Suvremena psihologija, 17(2), 111-124.

Argyle, M. (2001). The Psychology of Happiness. 2nd Edition. East Sussex: Routlege.

Barić, R., Cecić-Erpič, S., \& Babić, V. (2002). Intrinsic motivation and goal orientation in track-and-field children. Kinesiology, 34(1), 50-60.

Barić, R., Vlašić, J., \& Cecić-Erpič, S. (2014). Goal orientation and intrinsic motivation for physical education: Does perceived competence matter? Kinesiology, 46(1), 117-126.

Bassi, M., \& Delle Fave, A. (2004). Adolescence and the changing context of optimal experience in time: Italy 1986-2000. Journal of Happiness Studies, 5(2), 155-179.

Booth, F.W., \& Chakravarthy, M.V. (2002). Costs and consequences of sedentary living: New battleground for an old enemy. President's Council on Physical Fitness and Sports: Research Digest, 3, 1-7.

Bouillet, D., Ilišin, V., \& Potočnik, D. (2008). Continuity and Changes in Croatian University Students' Leisure Time Activities (1999-2004). Sociologija i prostor, 46(2), 123-142.

Brightbill, C.K. (1960). The challenge of leisure. Englewood Cliffs, NJ: Prentice Hall.

Buckworth, J., Lee, R.E., Regan, G., Schneider, L.K., \& DiClemente, C.C. (2007). Decomposing intrinsic and extrinsic motivation for exercise: Application to stages of motivational readiness. Psychology of Sport and Exercise, 8(4), 441-461.

Campbell, A., Converse, P.E., \& Rodgers, W.L. (1976). The Quality of American Life. New York: Russell Sage Foundation.

Caspersen, C.J., Pereira, M.A., \& Curran, K.M. (2000). Changes in physical activity patterns in the United States, by sex and cross-sectional age. Medicine and Science in Sports and Exercise, 32(9), 1601-1609.

Craft, B.B., Carroll, H.A., \& Lustyk, M.K.B. (2014). Gender Differences in Exercise Habits and Quality of Life Reports: Assessing the Moderating Effects of Reasons for Exercise. International Journal of Liberal Arts and Social Science, 2(5), 65.

Csikszentmihalyi, M., \& Rathunde, K. (1993). The measurement of flow in everyday life: toward a theory of emergent motivation. In: J. Jacobs (Ed.), Nebraska symposium on motivation: Developmental perspectives on motivation, 40, 57-97, Lincon, NE: University of Nebraska Press

Cvenić, J., Nagy, G., \& Šmit, D. (2014). Razlike u motivaciji za nastavu tjelesne i zdravstvene kulture između redovnih učenika i učenika koji dodatno pohađaju izvannastavne sportske aktivnosti - ,Viken- 
dom u sportske dvorane“ u OŠ Pavleka Miškine. 23. Ljetna škola kineziologa Republike Hrvatske, 185-190.

Cvitan, M., Doolan, K., Farnell, T., \& Matković, T. (2011). Socijalna $i$ ekonomska slika studentskog života u Hrvatskoj: nacionalno izvješće istraživanja EUROSTUDENT za Hrvatsku (2011.). Zagreb: Institut za razvoj obrazovanja.

Cury, F., Biddle, S., Famose, J.P., Sarrazin, P., Durand, M., \& Goudas, M (1996). Personal and situational factors influencing intrinsic interest of adolescent girls in school physical education: A structural equation modelling analysis. Educational Psychology, 16(3), 305-315.

Deci, E.L., Koestner, R., \& Ryan, R.M. (1999). A meta-analytic review of experiments examining the effects of extrinsic rewards on intrinsic motivation. Psychological Bulletin, 125(6), 627-668.

Deci, E.L., \& Ryan, R.M. (1985). Intrinsic motivation and self-determination in human behavior. New York and London: Plenum.

Deci, E.L., \& Ryan, R.M. (2000). The „what“ and „why“ of goal - pursuits: Human needs and the self - determination of behavior. Psychological Inquiry, 11(4), 227-268.

Deci, E.L., \& Ryan, R.M. (2008). Self-determination theory: A macrotheory of human motivation, development and health. Canadian Psychology, 49, 182-185.

Delle Fave, A., \& Bassi, M. (2000). The quality of experience in adolescents' daily lives: Developmental perspectives. Genetic, Social, and General Psychology Monographs, 126(3), 347-367.

Diener, E., \& Biswas-Diener, R. (2008). Happiness: Unlocking the Mysteries of Psychological Wealth. Malden: Blackwell Publishing.

Diener, E., Suh, E.M., Lucas, R.E., \& Smith, H.L. (1999). Subjective Well-Being: Three Decades of Progress. Psychological Bulletin 125(2), 276-302.

Douglas, K.A., Collins, J.L., Warren, C., Kann, L., Gold, R., Clayton, S., ... \& Kolbe, L.J. (1997). Results from the 1995 national college health risk behavior survey. Journal of American College Health, 46(2), 55-67.

Duckett, E., Raffaelli, M., \& Richards, M.H. (1989). "Taking care”: Maintaining the self and the home in early adolescence. Journal of Youth and Adolescence, 18(6), 549-565.

Ellis, G.D., \& Witt, P.A. (1991). Conceptualization and measurement of leisure: Making the abstract concrete. In: T.L. Goodale, P.A. Wit (Eds.), Recreation and leisure: Issues in an era of change (pp. 377-395). State College, PA: Venture Publishing, Inc.

Fox, K.R., \& Corbin, C.B. (1989). The physical self-perception profile: Devlopment and preliminary validation. Journal of Sport and Exercise Psychology, 11(4), 408-430.

Frederick-Recascino, C.M., \& Ryan, R.M. (1993). Differences in motivation for sport and exercise and their relations with participation and mental health. Journal of Sport Behavior, 16(3), 124-146.

Frederick-Recascino, C.M., \& Ryan, R.M. (1995). Self-determination in sport: A review using cognitive evaluation theory. International Journal of Sport Psychology, 26, 5-23.

Garst, B., Scheider, I., \& Baker, D. (2001). Outdoor adventure program participation impacts on adolescent self-perception. The Journal of Experiential Education, 24(1), 41-49.

Giacobbi, P.R., Hausenblas, H.A., \& Frye, N. (2005). A naturalistic assessment of the relationship between personality, daily life events, leisure-time exercise, and mood. Psychology of Sport and Exercise, 6(1), 67-81.

Greblo, Z., Pedišić, Ž., \& Jurakić, D. (2008). Relationship between exercise frequency and self-perceived mental health. In: D. Milanovic \& F. Prot (Eds.). Kinesiology research trends and applications (pp. 814-817). Zagreb: Faculty of Kinesiology.

Grunbaum, J.A., Kann, L., Kinchen, S.A., Williams, B., Ross, J.G., Lowry, R., \& Kolbe, L. (2002). Youth risk behavior surveillance - United States, 2001. Journal of School Health, 72(8), 313-328.

Hallal, P.C., Victora, C.G., Wells, J.C., \& Lima, R.D.C. (2003). Physical inactivity: prevalence and associated variables in Brazilian adults. Medicine and Science in Sports and Exercise, 35(11), 1894-1900.

Hogan, C.L., Mata, J., \& Carstensen, L.L. (2013). Exercise holds immediate benefits for affect and cognition in younger and older adults. Psychology and Aging, 28(2), 587-594.

Huta, V. (2007). Pursuing pleasure versus growth and excellence: Links with different aspects of well-being. Unpublished doctoral dissertation.

Huta, W., \& Ryan, R.M. (2010). Pursuing Pleasure or Virtue: The Differential and Overlapping Well-Being Benefits of Hedonic and Eudaimonic Motives. Journal of Happiness Studies, 11(6), 735-762.
Ingledew, D.K., \& Markland, D. (2008). The role of motives in exercise participation. Psychology and Health, 23(7), 807-828.

Iso-Ahola, (1999). Motivational foundations of leisure. In: Jackson \& Burton (Eds.), Understanding Leisure Recreation, Mapping the Past, Charting the Future (pp. 35-51). State College, PA: Venture Publishing.

Janssen, I., \& Leblanc, A. (2015). Systematic Review of the Health Benefits of Physical Activity and Fitness in School-Aged Children and Youth. In: School Nutrition and Activity: Impacts on Well-Being (pp. 183-219). Oakville: Apple Academic Press.

Kahneman, D., Diener, E., \& Schwarz, N. (Eds) (1999). Well-Being: The Foundations of Hedonic Psychology. New York: Russell Sage Found.

Kilpatrick, M., Hebert, E., \& Bartholomew, J. (2005). College students' motivation for physical activity: differentiating men's and women's motives for sport participation and exercise. Journal of American College Health, 54(2), 87-94.

Kleiber, D.A., Walker, G.J., \& Mannell, R.C. (2011). A social psychology of leisure (2nd ed.). State College, PA: Venture Publishing.

Larson, R.W., \& Verma, S. (1999). How children and adolescents spend time across the world: Work, play, and developmental opportunities. Psychological Bulletin, 125(6), 701-736.

Massimini, F., \& Carli, M. (1988). The systematic assessment of flow in daily experience. In: M. Csikszentmihalyi \& I. Csikszentmihalyi, (Eds.). Optimal Experience: Psychological studies of flow in consciousness (pp. 266-287). Cambridge: Cambridge University Press.

McAuley, E., Duncan, T., \& Tammen, V.V. (1989). Psychometric properties of intrinsic motivation inventory in a competitive sport setting: A confirmatory factor analysis. Research Quarterly for Exercies and Sport, 60(1), 48-58.

Newman, D.B., Tay, L., \& Diener, E. (2014). Leisure and Subjective WellBeing: A Model of Psychological Mechanisms as Mediating Factors. Journal of Happiness Studies, 15, 555-578.

Neulinger, J. (1974). The psychology of leisure: Research approaches to the study of leisure. Springfield. IL: Charles C. Thomas.

Norton, D.L. (1976). Personal Destinies: A Philosophy of Ethical Individualism. Princeton: Princeton University Press.

Reiner, M., Niermann, C., Jekauc, D., \& Woll, A. (2013). Long-term health benefits of physical activity-a systematic review of longitudinal studies. BMC Public Health, 13(1), 813

Rottensteiner, C., Tolvanen, A., Laakso, L., \& Konttinen, N. (2015). Youth athletes' motivation, perceived competence, and persistence in organized team sports. Journal of Sport Behavior, 38(4), 432.

Ryan, R.M., \& Deci, E.L. (2000). Self-determination theory and the facilitation of intrinsic motivation, social development, and well-being. American Psychologist, 55, 68-78.

Ryan, R.M., Frederick-Recascino, C.M., Lepes, D., Rubio, N., \& Sheldon, K.M. (1997). Intrinsic motivation and exercise adherence. International Journal of Sport Psychology, 28, 335-354.

Shaw, S.M., Kleiber, D.A., \& Caldwell, L.L. (1995). Leisure and identity formation in male and female adolescents: A preliminary examination. Journal of Leisure Research, 27(3), 245-263.

Smigel, E.O. (Ed.) (1963). Work and leisure: A contemporary social problem. New Heaven: College \& University Press.

Stone, E.J., McKenzie, T.L., Welk, G.J., \& Booth, M. (1998). Effects of physical activity interventions in youth: Review and synthesis. American Journal of Preventive Medicine, 15, 298-315.

Šimunić, V., \& Barić, R. (2011). Motivacija za vježbanje povremenih rekreativnih vježbača: Spolne razlike. Hrvatski Športskomedicinski Vjesnik, 26(1), 19-25.

Tkalčić, M., \& Lončarić, D. (1998). Characteristics of Sleeping and Dreaming in Psychology Students. Psihologijske teme, 6-7, 105-114.

Waterman, A.S. (1993). Two conceptions of Happiness: Contrasts of personal expressiveness (eudaimonia) and hedonic enjoyment. Journal of Personality and Social Psychology, 64(4), 678-691.

Waterman, A.S., Schwartz, S.J., \& Conti, R. (2008). The implications of two conceptions of happiness (hedonic enjoyment and eudaimonia) for the understanding of intrinsic motivation. Journal of Happiness Studies, 9, 41-79.

Yan, Z., Berger, B., Tobar, D., \& Cardinal, B.J. (2014). Reasons for exercise behavior among American and Chinese college women. Women in Sport and Physical Activity Journal, 22(1), 18-23.

Zeijl, E., Du Bois-Reymond, M., \& Te Poel, Y. (2001). Young Adolescents' Leisure Patterns. Society and Leisure, 24, 379-402. 